\title{
Educational upgrading and returns to skills in Latin America: evidence from a supply- demand framework
}

\author{
Pablo Acosta ${ }^{4}$, Guillermo Cruces $^{1,2}$, Sebastian Galiani ${ }^{3 *}$ and Leonardo Gasparini ${ }^{1}$
}

\author{
*Correspondence: \\ galiani@econ.umd.edu \\ ${ }^{3}$ University of Maryland, \\ College Park, USA \\ Full list of author information \\ is available at the end of the \\ article
}

\begin{abstract}
This paper documents the evolution of wage differentials and the supply of workers by educational level for sixteen Latin American countries over the period 1991-2013. We find a pattern of rather constant rise in the relative supply of skilled and semi-skilled workers over the period. Whereas the returns to secondary education fell over time, in contrast, the returns to tertiary education display a remarkable changing pattern common to almost all economies: significant increase in the 1990s, strong fall in the 2000s, and a deceleration of that fall in the 2010s. We conclude that supply-side factors seem to have limited explanatory power relative to demand-side factors in accounting for changes in the wage gap between workers with tertiary education and the rest.
\end{abstract}

Keywords: Returns to skills, Latin America, Inequality, Education

JEL Classification: $J 01$

\section{Introduction}

Income inequality dynamics in Latin America, one of the most unequal regions in the world, have been far from stable. While income dispersion significantly increased over the 1990s in most Latin American countries, the decade of 2000 was marked by a widespread fall in socioeconomic and labor disparities (López-Calva and Lustig 2010; Gasparini et al. 2011). ${ }^{1}$ Recent data for the 2010s suggest a slowing down of the pace of that fall and even indicate signs of stagnation and reversion in some economies (Gasparini et al. 2016). Understanding the drivers of these changing patterns is a difficult task, plagued by all sorts of methodological and data problems. In this paper, we contribute to that aim by providing evidence on patterns of wage skill premiums and labor supply by educational categories, exploiting a large database of microdata from harmonized national household surveys. Looking at wage premiums is important as the main source of inequality in household incomes (at least in the household incomes captured by surveys) is dispersion in earnings.

The analysis is based on a simple but illustrative supply and demand equilibrium framework that has been applied successfully to the study of returns to labor market

\footnotetext{
${ }^{1}$ Whereas patterns have been similar in most of the developing world, the size of the changes was significantly larger in Latin America (Alvaredo and Gasparini 2015)
} 
skills in developed countries (Katz and Murphy 1992; Goldin and Katz 2009) as well as in some developing economies (Montes Rojas 2006; Acosta and Gasparini 2007; Acosta and Montes Rojas 2008; Galiani 2009; Manacorda et al. 2010; Gallego 2012; García Swartz and Gasparini 2011). The methodology is based on an examination of changes in wage differentials and the relative supply of workers with different levels of educational attainment, from which consistent patterns in relative demand for skilled and unskilled labor can be derived. This framework is applied to a large database of microdata from harmonized Latin American national household surveys (SEDLAC database). In particular, we make use of more than 10 million individual observations in 250 surveys conducted in almost all countries in the region over the period 1991-2013.

Although there is heterogeneity across countries, we find a pattern of rather constant increase in the relative supply of skilled and semi-skilled workers over the period. Consistently, the returns to secondary education completion fell over time. However, in contrast, the returns to tertiary education display a remarkably changing pattern common to almost all economies: a significant increase in the 1990s, a strong fall in the 2000s, and a deceleration of that fall in the 2010s. We conclude that supply-side factors seem to have limited explanatory power relative to demand-side factors in accounting for changes in the wage skill premium.

The rest of the document is organized as follows. The next section explores the motivations for conducting this analysis, documenting briefly the secular expansion in education in the region and trends in income inequality over the last two decades. Section 3 describes the basic supply and demand framework to account for changes in wage skill premium and the relative supply of workers with different skill levels, whereas Sect. 4 presents and discusses the main results. Section 5 examines the role of supply and proxies for demand factors in the evolution of regional aggregates by means of regression analysis. Section 6 ends with some brief concluding remarks.

\section{Trends in education and inequality}

\subsection{Secular trends in education}

The stock of human capital is the main productive asset for households. As such, formal education constitutes one of the main determinants of an individual's income and is arguably a key to a wide set of economic and social opportunities. Latin America has experienced substantial changes in the educational attainment levels of its labor force in the second half of the twentieth century, and these have even accelerated over the last decades (see Fig. 1). This trend can be attributed to the expansion of both secondary and tertiary schooling, which followed an earlier rise in primary school enrollment during the 1960s-1980s. Despite a generalized upward trend in educational attainment of the labor force, there is still substantial heterogeneity between countries (Fig. 2). Only a minority of countries has an average of more than 9 years of education for adults in the 25-65 age range-this group includes those in the Southern Cone (Argentina, Chile, Uruguay) and Panama-while some countries in Central America (Guatemala, Honduras and Nicaragua) present a much smaller figure, with an average below 6 .

The Gini coefficient for years of education also fell steadily for all countries in the region during the 1990s and the 2000s. This indicator, however, is not sufficient to signal an unambiguous reduction in inequality of education. While persons from high and low 


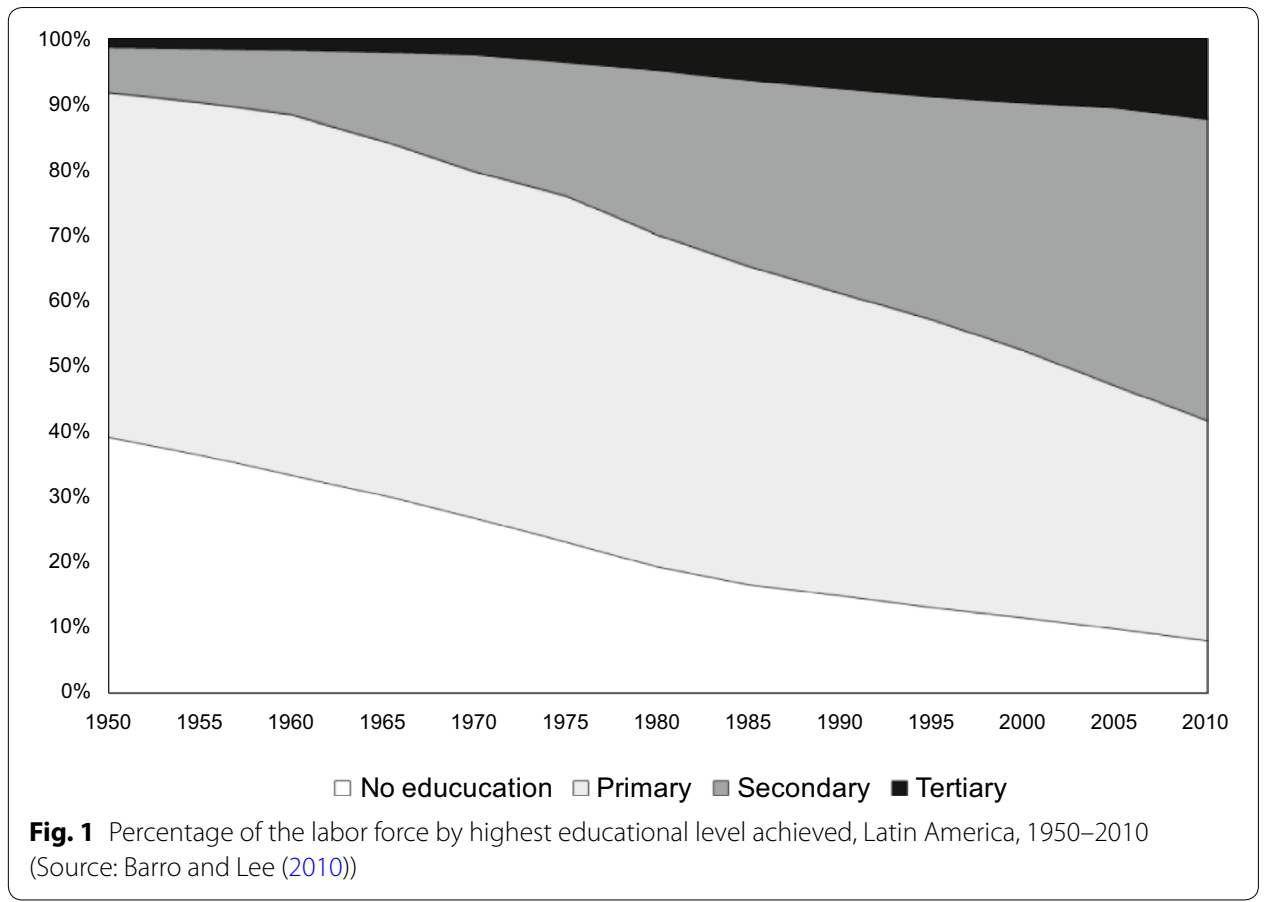

socioeconomic strata have seen their average levels of education increase, Cruces et al. (2014) report substantial differences for adults in the top quintile as compared to those in the bottom quintile; in some countries, the disparity is as large as 7.5 years. This quintile gap widened in almost all countries in the 1990s and got smaller in most countries in the 2000s. While the issue of whether or not inequality in education in the region has increased or not depends on which aspect and concept one attempts to capture, there is no ambiguity in the fact that average educational attainment has increased over time for all countries in the region. ${ }^{2}$

\subsection{Trends in income inequality}

In parallel to this educational expansion, there have been considerable changes in the patterns of income inequality in Latin America over the last decades (Fig. 3). Inequality soared in the 1990s and fell sharply in the 2000s. The contrast between the two decades has been widely documented and discussed in other studies (e.g., López-Calva and Lustig 2010; Gasparini et al. 2011; Gasparini and Lustig 2011; Azevedo et al. 2012; Cord et al. 2017). Gasparini et al. (2016) report that the mean Gini coefficient for the distribution of household per capita income in Latin America grew at a rate of 0.3 points per year between 1992 and 2002, and then, it fell 0.7 points a year between 2002 and 2010. That decline has substantially decelerated in the 2010s: The Gini fell 0.3 points per year between 2010 and 2014, less than half as much as in the previous period. These patterns are statistically significant, generalized within subregions of Latin America, and robust

\footnotetext{
${ }^{2}$ In this paper we restrict the analysis to the quantity dimension of education and ignore the very important quality dimension, since there are still severe data limitations to construct a comparable measure of education quality for the adult population across countries and over time.
} 


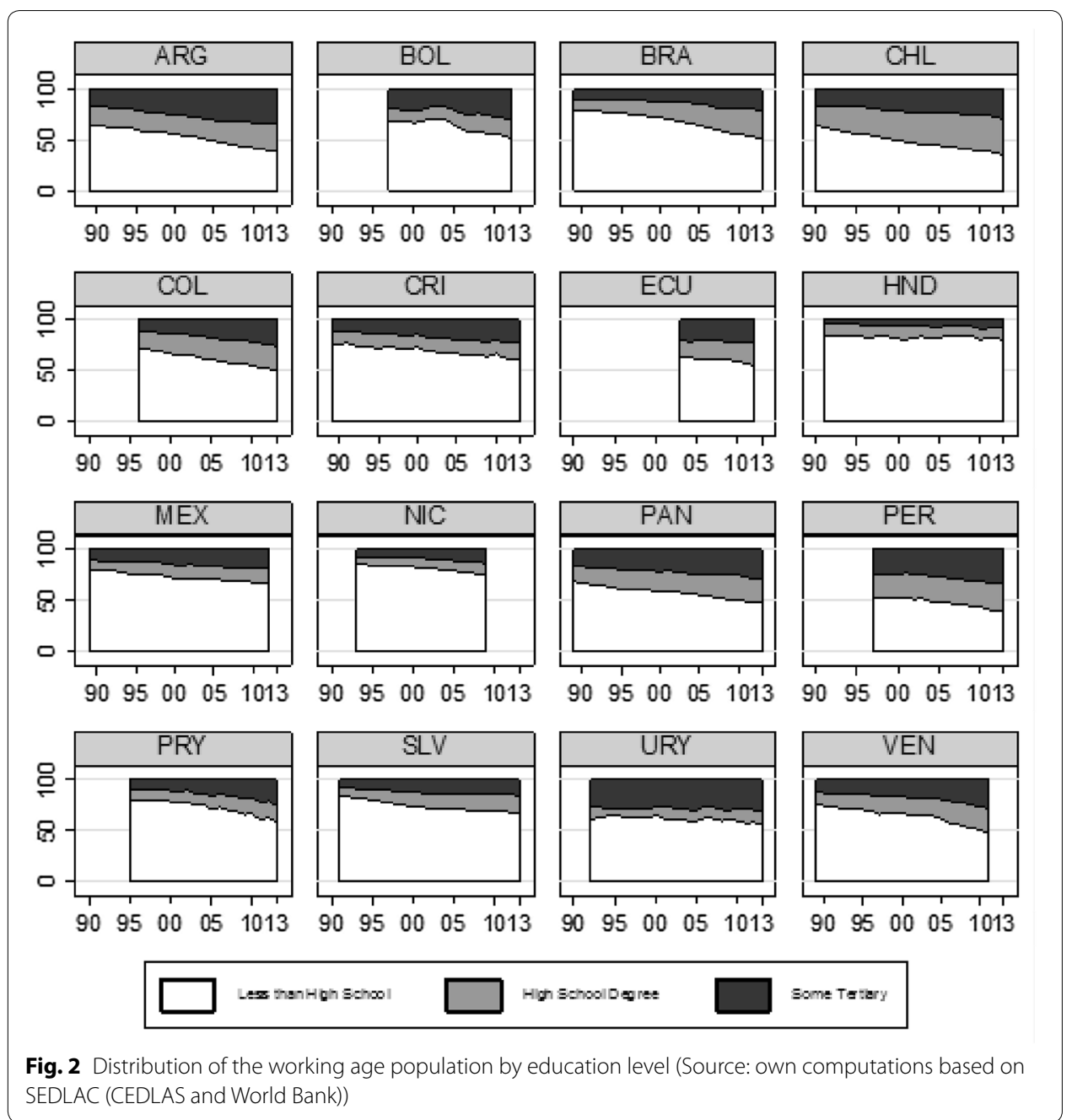

to various methodological decisions, including the consideration of various inequality indices (see SEDLAC Web site). As Fig. 3 suggests, they are also robust to the consideration of different samples of countries according to the availability and quality of their national household surveys. ${ }^{3}$

The multitude of policy changes, external shocks and country experiences imply that there is no single satisfying explanation for these trends, which can be attributed to a variety of factors. This paper explores one of the main channels that affect income distribution: changes in labor market returns to education. In principle, these changes are important for a simple reason: Earnings are the main source of income for most households. On average, they account for $75 \%$ of all income reported in Latin American household surveys. Moreover, several studies that apply different decomposition strategies confirm the leading role of the dispersion in earnings, and in particular in hourly wages, in accounting for inequality in the per capita income distribution (Azevedo et al. 2012; Alejo et al. 2013). Figure 4 is illustrative of the close relationship between income

\footnotetext{
${ }^{3}$ The sample of "9 countries" includes those with consistent data spanning the whole period 1991-2013.
} 


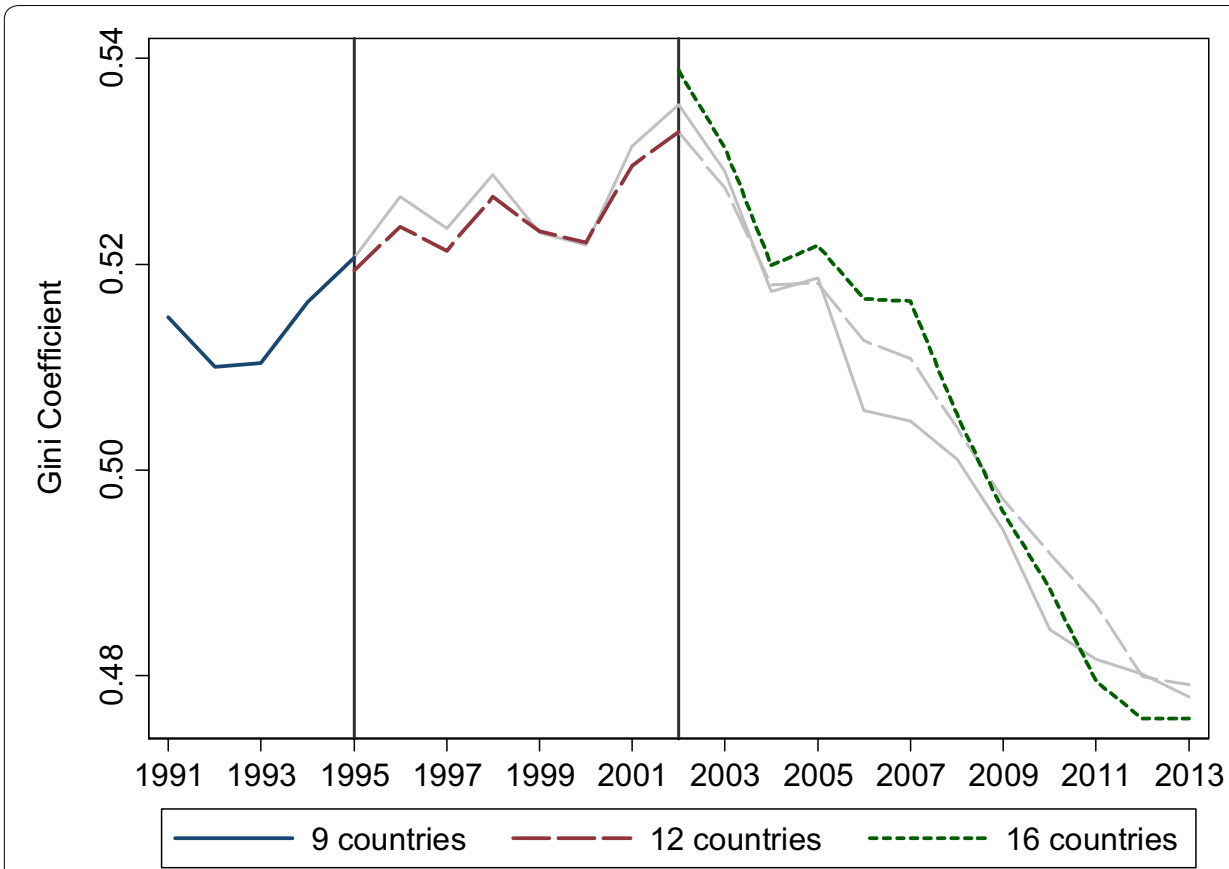

Fig. 3 Gini coefficient for the distribution of household per capita income. Unweighted average for Latin America, 1991-2013. "9 countries" refer to: Argentina, Brazil, Chile, Costa Rica, Honduras, Mexico, Panama, Uruguay, and Venezuela. "12 countries" also include: Colombia, Paraguay, and El Salvador. "16 countries" also include: Bolivia, Ecuador, Peru, and Nicaragua (Source: own computations based on SEDLAC (CEDLAS and World Bank))

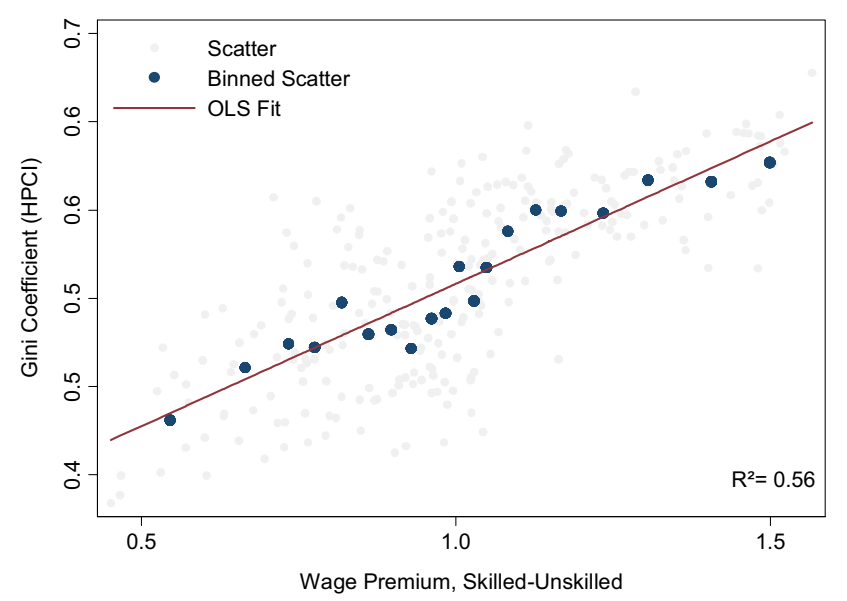

Fig. 4 Gini coefficient for the distribution of household per capita income and wage premium skill-unskilled. Latin America, 1991-2013 (Source: own computations based on SEDLAC (CEDLAS and World Bank))

inequality at the household level and the dispersion in wages, proxied by the wage gap between skilled and unskilled labor. (More details on the construction of this wage skill premium can be found below.) The figure suggests that the wage skill premium is a useful proxy for aggregate levels of inequality: Explaining the evolution of these differentials should prove useful for interpreting broader distributional changes in these economies. 


\section{Framework and empirical implementation}

\subsection{Methodology}

This section outlines an analytical framework to study changes in returns to education and to determine the relative contribution of supply and demand factors to the observed trends. In a seminal contribution, Tinbergen (1975) provides a framework to interpret the role of labor supply and demand factors in changes in returns to education. Tinbergen's discussion is often referred to as "the race between education and technology" because he postulated that secular technological change would favor the relative demand for skilled labor, increasing its relative remuneration (and thus overall inequality), whereas educational upgrading would provide a counterbalancing force, reducing this premium. This framework has been formalized, among others, by Katz and Murphy (1992), Card and Lemieux (2001), and Goldin and Katz (2009). As these authors show, it is possible to simplify the analysis by assuming two factors of production, corresponding to two levels of skills among workers-high and low. Inequality is mainly driven by the remuneration differential between these two groups, the wage skill premium, which in turn is determined by an interaction of the relative supply of high skill to low skill workers (which proxies for changes in the human capital composition of the workforce), and the corresponding relative demand for these two factors of production. In this simple supply and demand equilibrium framework, an increase in the relative supply of skilled workers should result in a decline in their relative remuneration, while a positive change in the relative demand for this type of workers would increase the wage skill premium.

Katz and Murphy's (1992) pioneer methodology has been applied to numerous country case studies in Latin America-for instance, for the 1990-2003 period in Mexico (Montes Rojas 2006), 1960-2000 in Chile (Gallego 2012), and 1980-2007 in Panama (Galiani 2009). More recently, Manacorda et al. (2010) develop a full-fledged analysis of the relationship between changes in the wage skill premium and in the relative supply of skilled workers for Argentina, Brazil, Chile, Colombia, and Mexico in the 1980s and the 1990s. They document a substantial rise in the supply of workers with some secondary education, and they find a decline in the relative wage of this group with respect to unskilled workers, consistent with the large increase in their supply. They also find a simultaneous rise in the relative wages of skilled workers, which they attribute to a generalized shift in the demand for workers with tertiary education.

\subsection{The model}

The basic framework in this paper assumes a production function with a constant elasticity of substitution (CES) and two factors, skilled (S) and unskilled (U) labor.

$$
Q_{t}=A_{t}\left[\lambda_{t} S_{t}^{\rho}+\left(1-\lambda_{t}\right) U_{t}^{\rho}\right]^{\frac{1}{\rho}}
$$

Total output $\mathrm{Q}$ is a function of the quantities of these factors and the technology parameters $\rho$ and $\lambda$. Given this production function, the elasticity of substitution between skilled and unskilled labor is $\sigma_{S U}=(1-\rho)^{-1}$.

This basic framework relies on two broad aggregates of labor. However, the educational structure of the Latin American population discussed in Sect. 2 suggests 
that the analysis of returns to skills would be enriched by studying the evolution of premiums, supply, and demand factors within the unskilled labor group. Following Goldin and Katz (2009), basic CES production function (1) can be augmented to accommodate three skill levels by partitioning the unskilled group. They propose a specification which maintains the previous CES setup, but considers $U$ to be a composite factor-a CES subaggregate of the form:

$$
U_{t}=\left[\theta_{t} H_{t}^{\eta}+\left(1-\theta_{t}\right) D_{t}^{\eta}\right]^{\frac{1}{\eta}}
$$

where $\theta$ and $\eta$ are additional technology parameters, and $H$ and $D$ are units of high school graduate labor and labor with less than a high school degree (referred to as high school dropouts), respectively. The (constant) elasticity of substitution between these two factors is $\sigma_{H D}=(1-\eta)^{-1}$.

Under perfect competition, with a large number of firms and factors paid at the marginal product value, the wage premium between skilled and unskilled workers $\left(w_{S} / w_{U}\right)$ and the differential wages between high school graduates and dropouts $\left(w_{H} / w_{D}\right)$ in year $t$ satisfy the following two relationships:

$$
\begin{aligned}
& \log \left(\frac{w_{S_{t}}}{w_{U_{t}}}\right)=\log \left(\frac{\lambda_{t}}{1-\lambda_{t}}\right)-\frac{1}{\sigma_{S U}} \log \left(\frac{S_{t}}{U_{t}}\right) \\
& \log \left(\frac{w_{H_{t}}}{w_{D_{t}}}\right)=\log \left(\frac{\theta_{t}}{1-\theta_{t}}\right)-\frac{1}{\sigma_{H D}} \log \left(\frac{H_{t}}{D_{t}}\right)
\end{aligned}
$$

The skilled-unskilled wage differential in Eq. (3) captures the traditional Katz and Murphy (1992) college premium, while Eq. (4) represents the high school premiumthe difference in wages within the two groups that constitute the unskilled aggregate. Large values for the elasticities of substitution $\sigma$ suggest that the two types of labor are close to perfect substitutes, and relative wages would then be uncorrelated with relative quantities.

A limitation of the Tinbergen framework and its subsequent applications, however, is that, despite its emphasis on both supply and demand factors, it does not provide for an unambiguous way to approximate changes in demand. This limitation is due to the difficulty of identifying simultaneous demand and supply movements from observed quantities and prices, which are, by definition, equilibrium points resulting from the intersection of the two corresponding curves. While the constructed supply and wage skill premiums also result from market equilibrium, it is plausible that the supply index, based on population stocks, represents the actual relative supply. Katz and Murphy (1992), and subsequent related studies, use observed wage premiums and relative changes in quantities of skilled and unskilled labor as measures of relative prices and supply, respectively; they then compute the changes in the relative demand of skilled labor as a residual-that is, as the figures that would be compatible with the observed changes in prices and supply for a given level of the elasticity of substitution between both factors. 


\subsection{Data and empirical implementation}

Evidence for this paper was obtained by processing microdata from national household surveys included in the Socioeconomic Database for Latin America and the Caribbean (SEDLAC), a project jointly developed by CEDLAS, at the Universidad Nacional de La Plata, and the World Bank. Household surveys are not uniform across Latin American countries, and in several cases, within a country over time. Thus, the issue of comparability is of great concern. Owing to this, we have made all possible efforts to make statistics comparable across countries and over time by using similar definitions of variables in each country/year and by applying consistent methods of processing the data (see SEDLAC (2015) for details on the harmonization process).

The document covers a set of 16 Latin American economies: Argentina, Brazil, Bolivia, Chile, Colombia, Costa Rica, Ecuador, El Salvador, Honduras, Mexico, Nicaragua, Panama, Paraguay, Peru, Uruguay, and Venezuela. Only Guatemala is missing among the continental Latin American countries. The sample represents $97.5 \%$ of the total Latin American population. We have drawn data from 258 national household surveys in these 16 countries over the period 1991-2013, containing information on wages, hours of work, education, and other relevant variables. We restrict the sample to individuals aged 26-56 that have fully coherent answers about income and education. Following Manacorda et al. (2010), we compute premiums from a sample of male workers only to control for the potential effects of the secular increase in female labor force participation. Even with these restrictions, our sample includes data from more than 10 million workers in Latin America.

Adopting an education-based measure of skills, skilled workers $(S)$ are defined as those with some tertiary education (either complete or not complete), while unskilled workers $(U)$ encompass workers with a high school diploma or lower educational attainment. $U$ is then divided into two groups, which correspond to workers with a high school degree $(H)$ and those with a lower level of education (referred to as high school dropouts) $(D)$, respectively.

The two wage skill premiums (left-hand side terms on Eqs. 3 and 4) and the relative supplies of labor (last terms on the right-hand side) are constructed from household survey data for each country. Intuitively, the skill premiums are derived from wage differentials in Mincer-type wage regressions, while the relative supplies are weighted functions of the proportions of each group of workers in the population.

We use the working age population as a basis for the relative labor supply, although the trends described in this paper are qualitatively the same if, instead of using population, we construct our measures of relative supply based on the labor force, employment, or hours of work. The relative supplies represent a weighted sum of individuals in each of the skill categories. Following Katz and Murphy (1992) and Goldin and Katz (2009), we first compute efficiency units dividing the population of each country into 24 groups (cells) according to their gender, educational level, and potential experience. ${ }^{4}$ For each cell, we compute the average wage for all years with respect to the wage of the largest group in the last year of the sample. These relative wages constitute the factors used to

\footnotetext{
${ }^{4}$ Four educational levels (complete college, incomplete college, complete secondary, and less than complete secondary) and three groups of potential experience (0 to 15 years, 16 to 30 years, and more than 30 years) are considered.
} 
weight the supply for each cell in efficiency units. These efficiency-adjusted labor supplies are then added for all skilled and unskilled workers, and their ratio (in logs) is the measure of relative supply in efficiency units. The relative supply of high school graduate workers with respect to dropouts is derived analogously. The two terms on the righthand side of Eqs. (3) and (4) correspond to the log of the relative supply aggregates.

The skill premiums, in turn, correspond to weighted averages of the coefficient for each educational category (primary, secondary, and tertiary, each then divided into complete and incomplete) in a Mincer regression for each country and year in the sample. The weights are given by the share of employment of individuals with a given educational level during a base period. See "Appendix" for more details.

A residual relative demand can be computed from these relative supplies and premiums. As shown by Katz and Murphy (1992), under perfect competition and considering a CES technology with two factors (skilled and unskilled workers), we can obtain a time series of relative demand between skilled and unskilled workers for a given value of the elasticity of substitution between factors $\sigma_{S U}$ :

$$
D_{t}=\sigma_{S U} \ln \left(\frac{w_{S t}}{w_{U t}}\right)+\ln \left(\frac{S_{t}}{U_{t}}\right)
$$

Estimates of the elasticities of substitution are needed to empirically compute Eq. (5). Most of the literature arrives at those estimates from the inverse of the coefficient of the relative supply of skilled labor in a wage gap regression, controlling by proxies of the relative demand-usually a time trend, linear, or of higher order. The mean value of $\sigma$ in our regression analysis indicates values fluctuating around 4, while Manacorda et al. (2010) find values around 3 for Latin America. Goldin and Katz (2009), in the context of the USA, report values of around 1.6. The tables in the document will show results, alternatively, for $\sigma$ equal to 2,3 , and 4 .

\section{Empirical results}

Table 1 presents the results for the skilled-unskilled (tertiary educated workers vs. the rest) wage premium and relative supplies, as well as the residual estimates of relative demand for different values of the elasticity of substitution. The period under analysis is divided into three "episodes" that roughly correspond to the 1990s, the 2000s, and the 2010s. Figure 5 presents aggregate trends, net of country effects (i.e., as deviations of each country's means). Although there is substantial heterogeneity across the countries in our sample, some patterns are common to most economies in the region. The relative supply of skilled workers increased substantially and continuously over the period under analysis, on average at approximately the same rate over the three episodes. This sustained and remarkable education upgrading of the region's workforce is consistent with the trends in the population outlined briefly in Sect. 2 .

The pattern for the wage premium in Table 1 exhibits heterogeneity both across countries and in particular over time. The wage skill premium increased for all countries in the region during the 1990s, modestly in some countries such as Brazil, Chile, Costa Rica, Honduras and Panama, and substantially more in the remaining countries in the sample, especially Argentina, Colombia, Nicaragua, and Uruguay. On the contrary, during the decade of 2000 , the wage skill premium fell in all countries; 


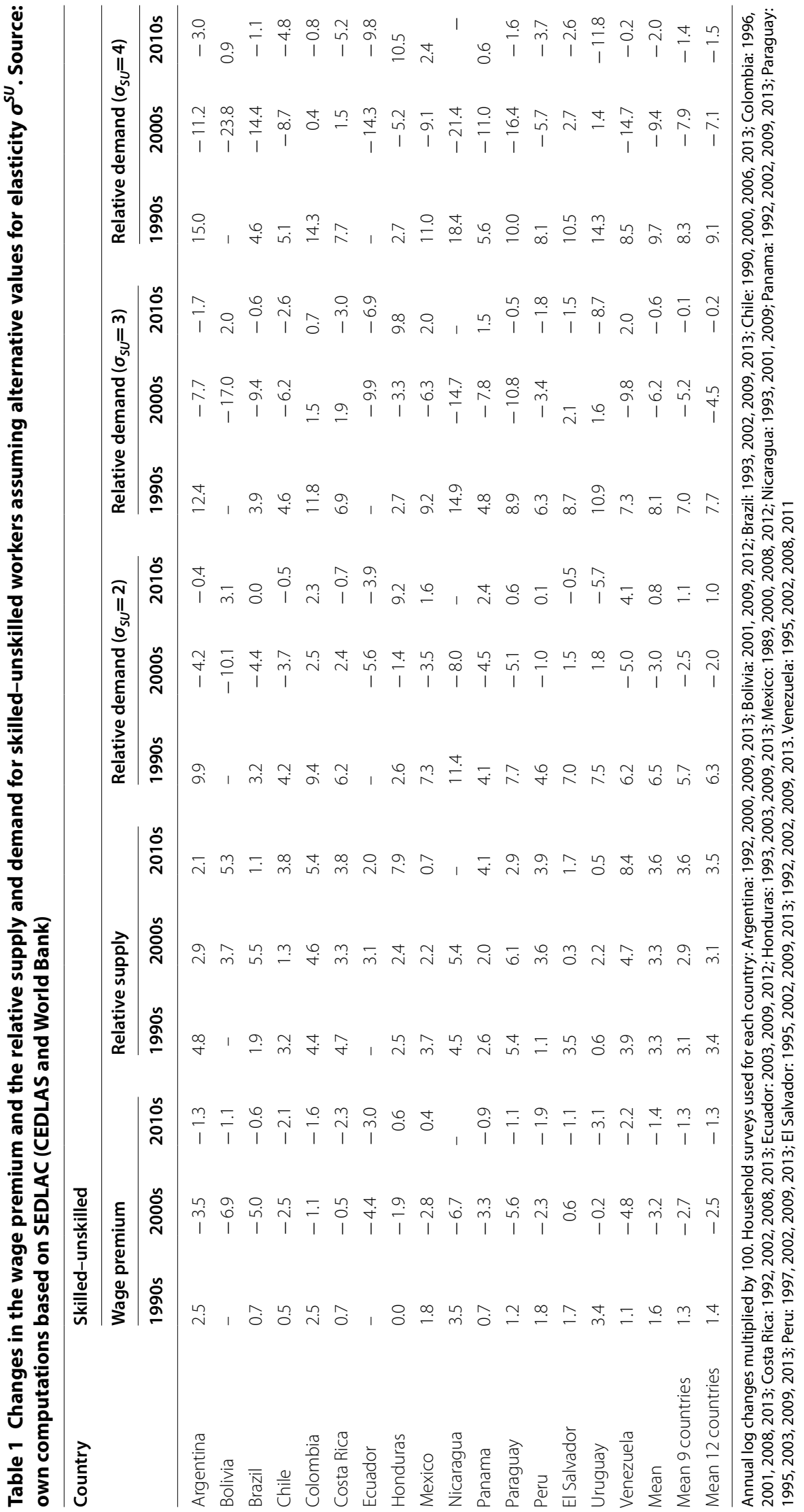




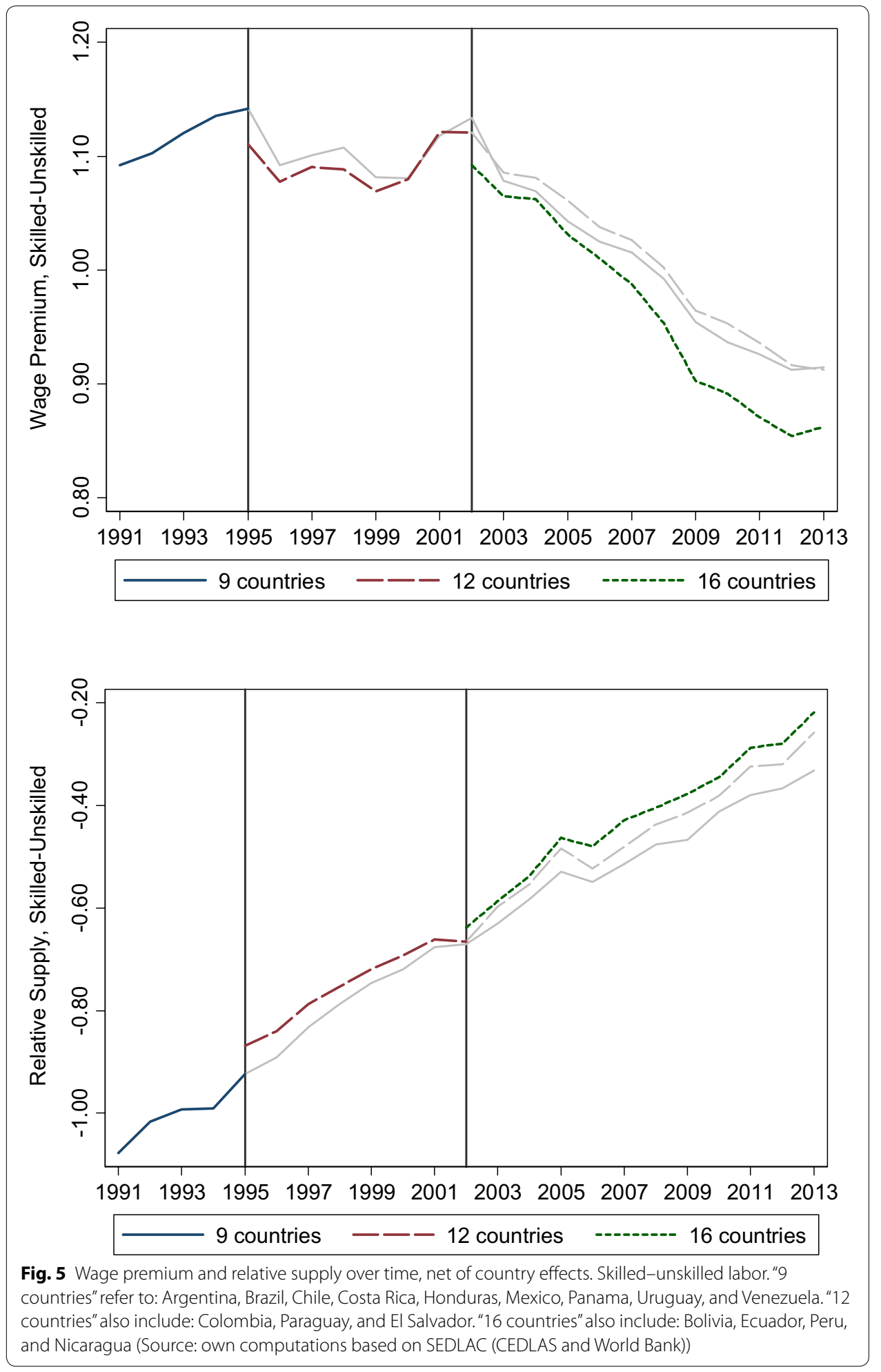

the average rate of reduction was about $3.2 \%$ per year, twice the size of the average increase in the previous decade. In most countries, the fall in the wage skill premium in the 2000s was enough to offset the increase of the 1990s. The decline began in the late 1990s in some economies (e.g., Mexico) and later in other South American 
economies that experienced serious macroeconomic crises (e.g., Argentina, Paraguay, and Uruguay). The reduction in the wage gap continued throughout the 2000s until signs of deceleration showed up in several economies around the turn of the decade. According to our estimates, while the wage premium fell at $3.2 \%$ on average in the 2000 s, the reduction slowed down to $1.4 \%$ per year in the 2010 s.

On average, then, the wage gap between skilled and unskilled workers widened in the 1990s and shrunk considerably in the 2000s and more slowly in the 2010s, in the context of a seemingly secular increase in the relative supply of skilled workers (Fig. 5). Interestingly, this pattern is remarkably similar to the one for the Gini coefficient of the distribution of household per capita income (Fig. 3). This similarity is partly due to the relevance of wage gaps in driving earnings and household inequality, given that labor income is the main income source for households in Latin America, but it could also be the consequence of factors affecting wage skill premiums and other income sources (e.g., public transfers, capital incomes, pensions) or demographic variables in the same direction.

The patterns in wage skill premiums and relative labor supply are consistent with a positive and strong increase in the relative demand for skilled labor in the 1990s in all countries, as witnessed by the estimates of residual demand presented in the last three panels of Table 1 and in the aggregate estimates in Fig. 7. The estimates of relative demand for the 2000s, consistent with the observed changes in relative supply and wage gaps, indicate a reversal in the trends of the previous decade. The indicators signal a negative shift in the relative demand for skilled labor; the decline was stronger in the 2000s and mild in the 2010s.

Besides changes in relative remuneration between workers with some tertiary education and those with lower levels of education, the analysis also allows for differentiating within the group of unskilled workers. The estimates that divide the group of the unskilled into high school graduates and high school dropouts or less educated, are presented in Table 2. As described in Sect. 2, the supply of workers with secondary education increased as compared to that of workers with lower education levels for most countries and periods under study, with only a few exceptions. Table 2 indicates a somewhat faster rate of expansion in the 2000s than in the 1990s and an acceleration in the 2010s.

These mostly uniform trends in the relative supply of secondary school graduates, however, did not translate into common trends in the wage gaps. During the 1990s, the wage differential between high school graduates and dropouts significantly increased in Argentina and Peru and substantially fell in Brazil, Colombia, Mexico, and El Salvador. The increase in the relative supply of high school graduates in the 2000s was concurrent with a decline in the relative remuneration of this factor in most countries, with a few exceptions, including Uruguay, where the relative supply of high school graduates fell over the period. The reduction in the skill premium between high school graduates and dropouts continued in the 2010s, although it was less generalized and intense.

The results in Table 2 and Fig. 6 indicate that, on average and concurrent with a sharp rise in the supply of high school graduates with respect to dropouts, the average wage differential between the two groups fell modestly over time and more strongly 


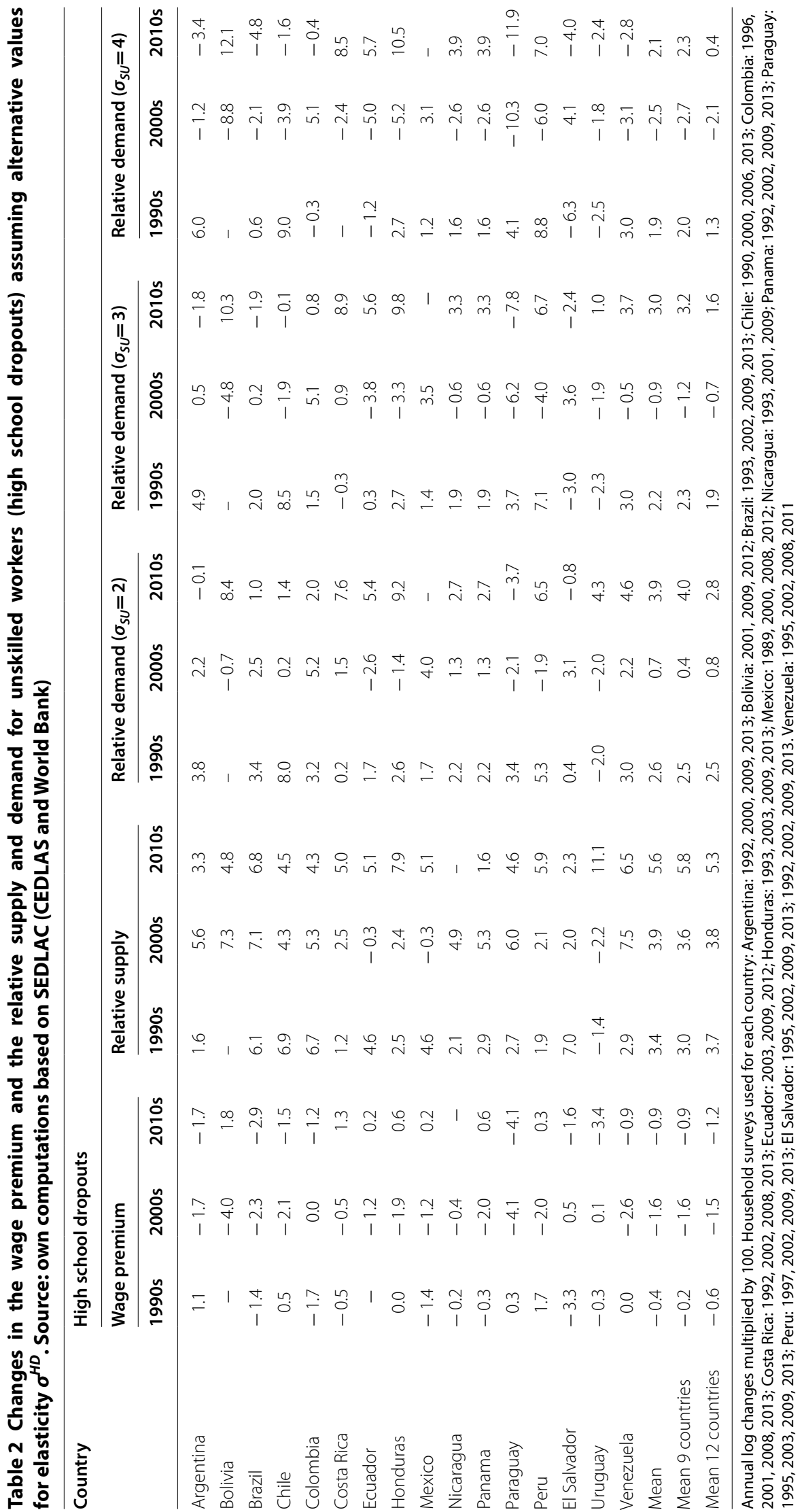



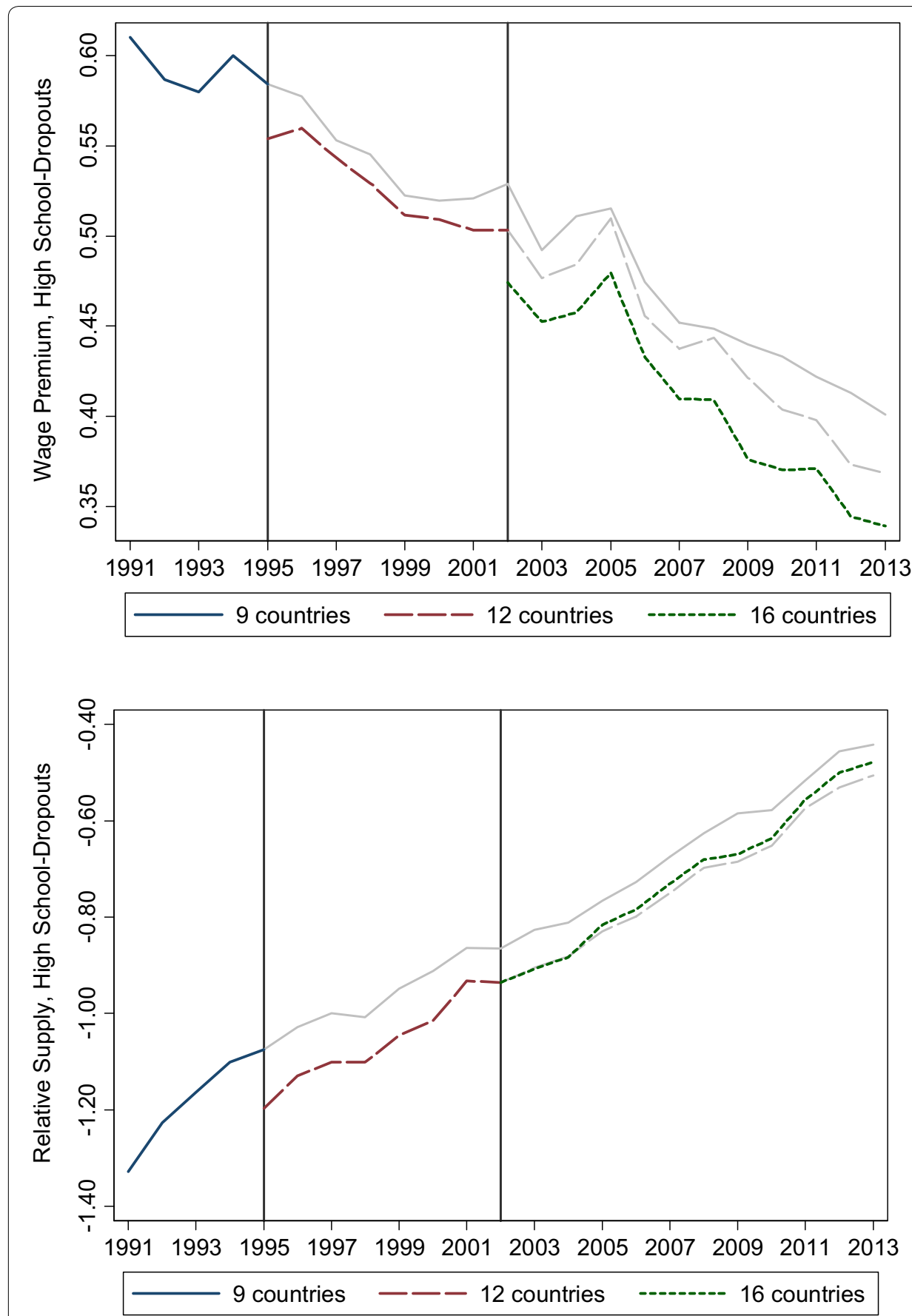

Fig. 6 Wage premium and relative supply over time, net of country effects. High school dropouts."9 countries" refer to: Argentina, Brazil, Chile, Costa Rica, Honduras, Mexico, Panama, Uruguay, and Venezuela. "12 countries" also include: Colombia, Paraguay, and El Salvador. "16 countries" also include: Bolivia, Ecuador, Peru, and Nicaragua (Source: own computations based on SEDLAC (CEDLAS and World Bank))

in the 2000s. These patterns are consistent with an increase in the relative demand for high school graduates with respect to dropouts, although at a slower pace than the increase in their relative supply (Fig. 7). 

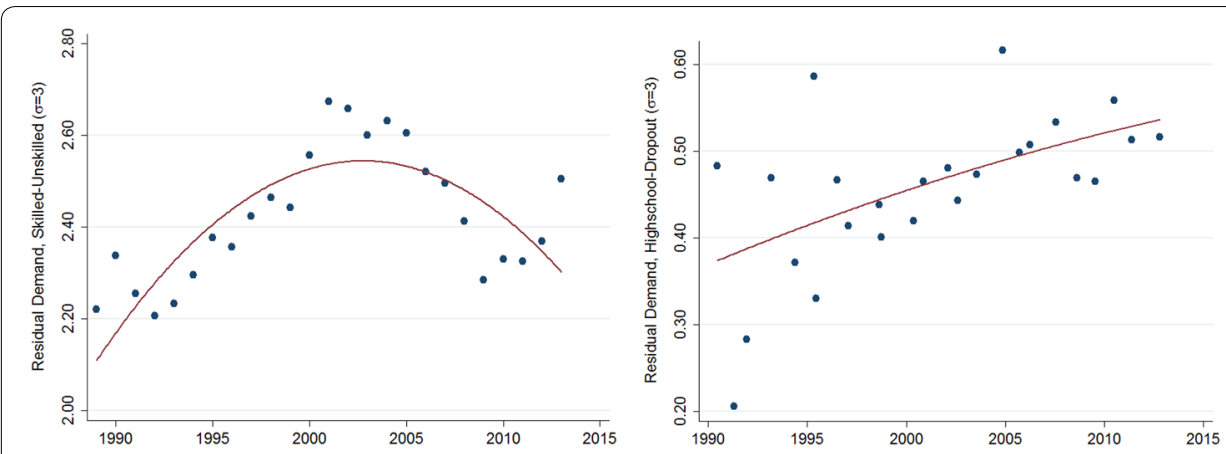

Fig. 7 Relative demands over time (residual assuming $\sigma=3$ for both elasticities) (Source: own computations based on SEDLAC (CEDLAS and World Bank))

\section{Wage skill premium and relative skill supply}

This section further explores some of the correlations that emerged from the descriptive analysis of the previous section. The methodology follows Katz and Murphy's (1992) study of the USA, which was based on time series regressions of the wage skill premium as a function of the relative supply of skilled labor and other factors. Here, and following Manacorda et al. (2010), pooled data from all the countries in the sample are used. The advantage of pooling the data for the region is that it allows for the inclusion of countries for which the limited number of years is not suitable for a country-specific regression. The results, thus, should be interpreted as reduced form estimates of averages for the whole region, with the caveat that the aggregate patterns do not necessarily correspond to the experiences of all 16 countries. ${ }^{5}$

The wage skill premium regressions a la Katz and Murphy (1992) attempt to establish the relevance of supply and demand factors. In this framework, however, there is no unambiguous indicator of relative demand. The literature for the USA has thus proxied these factors by adopting different specifications of time trends (Goldin and Katz 2009; Acemoglu and Autor 2011, among many others). The conjecture that time trends might adequately capture the shifts in relative demand seems to obey to the implicit assumption that the driving force behind these shifts is a relatively steady trend determined by cumulative factors, such as technological change. This assumption, however, does not seem to suit the nature of changes in Latin American economies. While technical change is probably a relevant force behind the demand for skilled labor in the region, a multitude of other factors can be expected to play a role, either directly mediating the forces of technological change (for instance, through relative prices of technology embedded in capital) or indirectly-for instance, external shocks, macroeconomic crises and the ensuing devaluations (which affect the relative price of capital with respect to labor), structural reforms (such as trade liberalization and privatizations, with direct effects on employment and demand for skills), and policy reversals. These types of events, more common in Latin American economies than in the advanced countries traditionally studied in Katz and Murphy type of analysis, imply that time trends might be unable to

\footnotetext{
$\overline{5}$ Given the large differences in population and size of the economies, the results are presented as unweighted country averages.
} 
Table 3 Correlates of the skilled-unskilled wage premium. Source: own computations based on SEDLAC (CEDLAS and World Bank) and WDI (World Bank)

\begin{tabular}{|c|c|c|c|c|c|}
\hline & (1) & (2) & (3) & (4) & (5) \\
\hline $\begin{array}{l}\text { Relative supply } \\
\mathrm{S}-U\end{array}$ & $-0.2111[0.166]$ & $\begin{array}{l}-0.4651 \\
{[0.082]^{* * *}}\end{array}$ & $\begin{array}{l}-0.4928 \\
{[0.145]^{* * *}}\end{array}$ & $\begin{array}{l}-0.4792 \\
{[0.145]^{* *}}\end{array}$ & $-0.3705[0.129]^{* *}$ \\
\hline Constant & $0.9220[0.086]$ & $0.6936[0.021]$ & $0.6333[0.098]$ & 0.1461 [1.189] & $0.3451[1.025]$ \\
\hline $\begin{array}{l}\text { Country-fixed } \\
\text { effects }\end{array}$ & No & Yes & Yes & Yes & Yes \\
\hline Year-fixed effects & No & No & Yes & Yes & Yes \\
\hline Countries & 16 & 16 & 16 & 9 & 12 \\
\hline Observations & 269 & 269 & 269 & 174 & 225 \\
\hline R-squared & 0.058 & 0.928 & 0.952 & 0.966 & 0.960 \\
\hline
\end{tabular}

Robust standard errors in brackets, clustered at the country level. Weights: inverse of the standard error of the skill premium squared

* Significant at 10\%; ** significant at 5\%; ${ }^{* * *}$ significant at $1 \%$

Table 4 Correlates of the high school-dropout wage premium. Source: own computations based on SEDLAC (CEDLAS and World Bank) and WDI (World Bank)

\begin{tabular}{|c|c|c|c|c|c|}
\hline & (1) & (2) & (3) & (4) & (5) \\
\hline $\begin{array}{l}\text { Relative supply } \\
\quad H-D\end{array}$ & -0.0354 [0.057] & $\begin{array}{l}-0.2829 \\
{[0.030]^{* * *}}\end{array}$ & $\begin{array}{l}-0.2822 \\
{[0.053]^{* * *}}\end{array}$ & $\begin{array}{c}-0.3203 \\
{[0.064]^{* * *}}\end{array}$ & $\begin{array}{l}-0.2897 \\
{[0.060]^{* * *}}\end{array}$ \\
\hline Constant & $0.4601[0.085]$ & $0.2378[0.015]$ & $0.2422[0.054]$ & $-0.4892[1.266]$ & $-0.5420[1.177]$ \\
\hline $\begin{array}{l}\text { Country-fixed } \\
\text { effects }\end{array}$ & No & Yes & Yes & Yes & Yes \\
\hline Year-fixed effects & No & No & Yes & Yes & Yes \\
\hline Countries & 16 & 16 & 16 & 9 & 12 \\
\hline Observations & 269 & 269 & 269 & 174 & 225 \\
\hline$R$-squared & 0.007 & 0.959 & 0.964 & 0.970 & 0.966 \\
\hline
\end{tabular}

Robust standard errors in brackets, clustered at the country level. Weights: inverse of the standard error of the skill premium squared

* Significant at $10 \%$; ** significant at $5 \%$; *** significant at $1 \%$

capture the potential changes, swings, and reversals in the pattern of relative demand for skilled labor.

With these limitations in mind, the analysis here follows Manacorda et al. (2010) approach, where no explicit proxy for relative demand is included. Instead, country- and year-fixed effects capture the demand shifters in the right-hand side of Eqs. (3) and (4). ${ }^{6}$ The regressions for the college wage premium have the following form:

$$
\log \left(\frac{w_{S}}{w_{U}}\right)_{c t}=\alpha+\beta \log \left(\frac{S}{U}\right)_{c t}+\sum C_{c}+\sum T_{t}+\varepsilon_{c t}
$$

where the left-hand side variable is the wage skill premium in year $t$ for country $c$, and the right-hand side variables are a constant, the relative supply of skilled labor, and country $(C)$ - and year ( $T$ )-fixed effects. The regressions for the high school premium are defined analogously.

\footnotetext{
${ }^{6}$ The fixed effects specification is more flexible than other alternatives, such as fitting linear trends, and thus allows for a better identification of the underlying effects.
} 


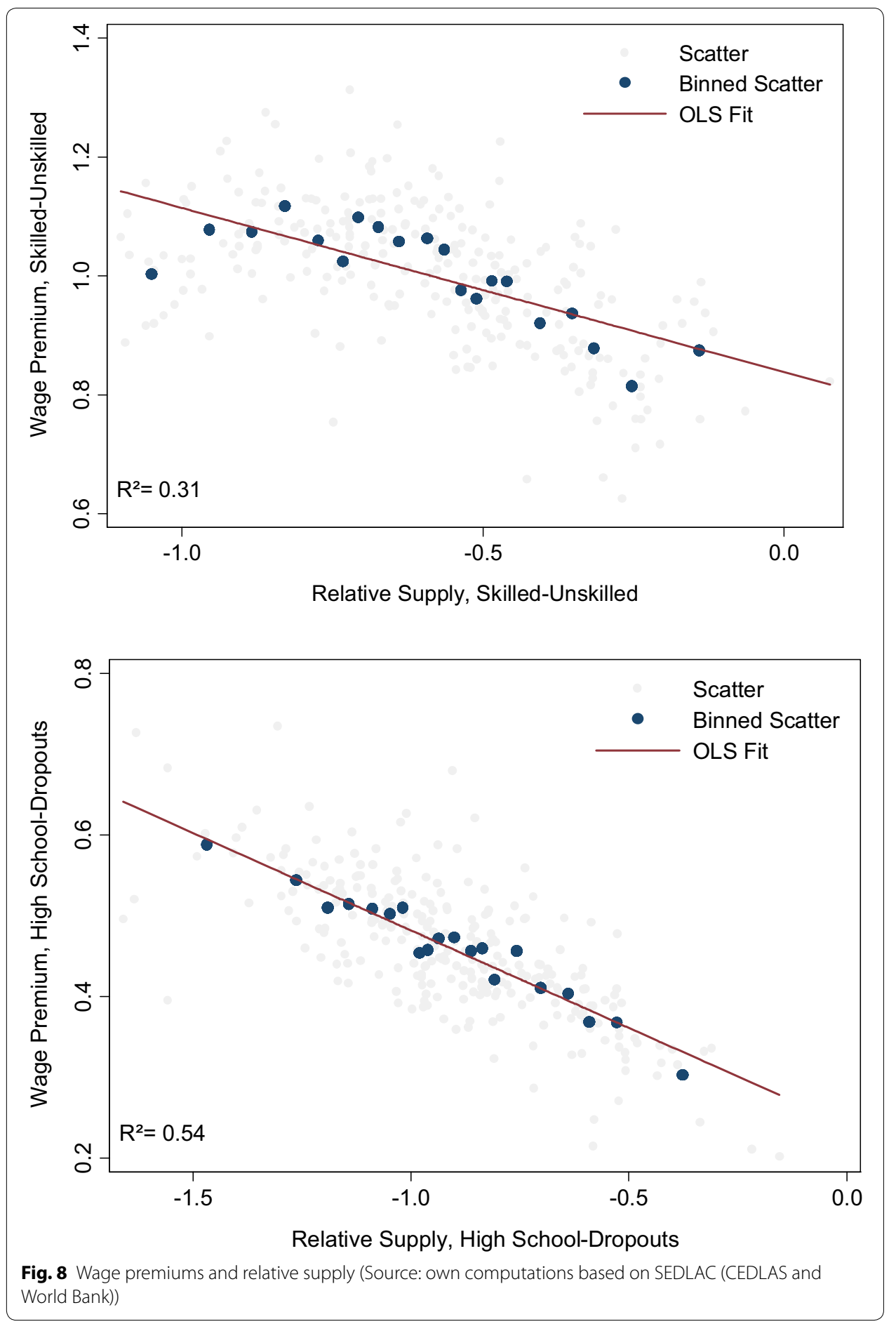

The results for these specifications are presented in Table 3, while the regressions with the high school premium as the dependent variable are presented in Table $4 .{ }^{7}$ As can be expected given the aggregate patterns in Fig. 8 (and from the country-specific scatter plots

\footnotetext{
${ }^{7}$ We present the results of the weighted regressions, where weights are the inverse of the standard error of the skill premium squared. Results for the unweighted regressions, available upon request, are similar.
} 
not presented in the paper), the simple correlations between the levels of the wage differentials and the respective relative supplies are negative and strongly significant, even when including country-fixed effects, year effects, and when clustering standard errors by country.

This evidence is compatible with the Tinbergen framework and the Katz and Murphy (1992) results for the USA: The educational upgrading of the labor force, manifested through an increase in the relative supply of workers with some college education or with a high school degree, implied on its own a decline in relative remunerations. The effect seems to have been stronger for the skilled-unskilled wage premium than for the high school-dropout differential.

\section{Conclusion}

This paper studies the evolution of wage differentials and trends in the supply and demand of workers by skill level (as proxied by educational attainment) for 16 Latin American countries, during the period 1991-2013. Although there is considerable heterogeneity across countries, we find a rather consistent rise in the relative supply of skilled and semi-skilled workers over the period. Consistent with this pattern, the returns to secondary education completion fell over time. By contrast, the returns to tertiary education display a remarkable changing pattern common to nearly all countries. The wage premium to that educational level significantly increased in the 1990s and fell strongly in the 2000s and more slowly in the early 2010s. Given this, we conclude that supplyside factors seem to have limited explanatory power relative to demand-side factors in accounting for changes in the wage skill premium, especially between workers with tertiary education and the rest. This result is relevant for policy as it suggests that improving overall quality of education, in particular if it is better aligned with the needs of the labor sector, could mitigate inequality concerns (by addressing labor demand shortages).

This finding stresses the need to further our understanding of the changes in the relative demands for skilled and unskilled labor and open several avenues for further research. It would be interesting to conduct much more detailed analysis of changes in labor demand and skill differences with more granular definitions of skills. Our multicountry study relies on a trustworthy but rather limited proxy, years of schooling. It would also be useful to complement our findings with a better understanding of the role of technological change and its impact on relative labor demand in the region. As we stressed in our discussion, demand factors are obtained as residuals in our framework, and we do not have any direct measure of technical change to contrast its importance as an explanatory factor. These types of more detailed analyses are more feasible in a country-by-country basis, since our regional approach necessarily implies the loss of details and specificities that can be gained with in-depth case studies.

\section{Abbreviation}

LAC: Latin America and the Caribbean.

\section{Acknowledgements}

The authors are grateful for comments from (and conversations with) Cristian Aedo, David Autor, Verónica Amarante, Augusto De La Torre, François Bourguignon, Claudia Goldin, Michael Crawford, Francisco Ferreira, Gary Fields, John Gilles, Tim Gindling, Margaret Grosh, Lawrence Katz, Marco Manacorda, Julian Messina, Ricardo Perez Truglia, Jamele Rigolini, lan Walker, and seminar participants at the World Bank, the OECD Development Center, Harvard's David Rockefeller Center for Latin American Studies, LaborAL project meeting (Buenos Aires), Academia Nacional de Ciencias Económicas (ANCE-Buenos Aires), and the Banco Central (Argentina). Javier Alejo, Julián Amendolaggine, Santiago Garganta, and Emmanuel Vázquez provided outstanding research assistance. 


\section{Authors' contributions}

All authors read and approved the final manuscript.

\section{Funding}

This paper is an updated and modified version of the working paper "Educational Upgrading and Returns to Skills in Latin America: Evidence from a Supply-Demand Framework, 1990-2010,"World Bank Policy Research Paper 5921, 2011. The original document was a background paper for the World Bank report Skills for the 21 st Century in LCR. The authors also acknowledge support from the CEDLAS-IDRC LaborAL (http://www.Labor-AL.org) project. The new version of this document was started as part of G. Cruces'visiting fellowship in 2013 at Harvard's David Rockefeller Center for Latin American Studies (DRCLAS), whose support is greatly appreciated.

Availability of data and materials

The data used for the computations in this paper will be made available on the corresponding author's webpage (S. Galiani).

\section{Competing interests}

The authors declare that they have no competing interests.

\section{Author details}

${ }^{1}$ CEDLAS-FCE-UNLP (Centro de Estudios Distributivos, Laborales y Sociales-Facultad de Ciencias Económicas-Universidad Nacional de La Plata), CONICET (Comisión Nacional de Investigaciones Científicas y Tecnológicas), La Plata, Argentina. ${ }^{2}$ University of Nottingham, Nottingham, UK. ${ }^{3}$ University of Maryland, College Park, USA. ${ }^{4}$ World Bank and IZA, Washington, USA.

\section{Appendix}

\section{Empirical calculations of wage premium}

Wage premiums are estimated by means of a Mincer wage regression, based on individual worker's microdata. The Mincer equation consists of a regression of the logarithm of the hourly wages on dummies for educational levels, a potential experience variable (constructed as age minus years of education minus 6) and its powers up to the order of 4 , and a series of regional and urban-rural controls. The remuneration for each input (ln $w_{k t}$ ) is computed from this regression as a weighted average of the returns to education of each of the educational levels belonging to the corresponding input. The wage premiums are then obtained as the difference of these remunerations. The regressions have the following form:

$$
\ln w_{i t}=\alpha+\beta_{\text {c.coll } t} D_{\text {c.coll } t}+\beta_{\text {i.coll } t} D_{\text {i.coll } t}+\beta_{\text {c.sec } t} D_{\text {c.sec } t}+\beta_{\text {i.sec } t} D_{\text {i.sec } t}+\beta_{\text {c.pri } t} D_{\text {c.pri } t}+\delta X_{i t}+\varepsilon_{i t}
$$

where $w$ is the wage for worker $i$ at time $t$, the $D$ variables are indicators for the level of educational attainment (college complete and incomplete, secondary complete and incomplete, and primary complete-primary incomplete is the omitted category) with their corresponding $\beta$-coefficients, and the $X$ variables represent a set of individual characteristics, which include years of experience, region of residence, and urban/rural status (when available).

Defining skilled workers as those with some college (complete or incomplete) and the unskilled as those without any college education, the corresponding skilled-unskilled wage premium is given by:

$$
\ln \left(\frac{w_{S t}}{w_{U t}}\right)=\left[\gamma_{\text {c.coll S }} \beta_{\text {c.coll } t}+\gamma_{\text {i.coll S }} \beta_{\text {i.coll } t}\right]-\left[\gamma_{\text {c.sec } \mathrm{U}} \beta_{\text {c.sec } t}+\gamma_{\text {i.sec } \mathrm{U}} \beta_{\text {i.sec } t}+\gamma_{\text {c.pri U }} \beta_{\text {c.pri } t}\right]
$$

where $\beta_{i t}$ is the coefficient associated with educational level $i$ in the Mincer equation at time $t$, and $\gamma_{i k}=E_{i} / E_{k}$ is the share of employment of the individuals with the educational level $i$ in the employment of input $k$ in a base period. ${ }^{8}$

\footnotetext{
${ }^{8}$ As in Katz and Murphy (1992), the base period is defined here as the average of all years for each country.
} 


\section{Analogously, the high school-dropout wage premium or differential can be obtained} as:

$$
\ln \left(\frac{w_{H t}}{w_{D t}}\right)=\beta_{\mathrm{c} . \sec t}-\left[\gamma_{\mathrm{i} . \sec \mathrm{D}} \beta_{\mathrm{i} . \mathrm{sec} t}+\gamma_{\mathrm{c} . \operatorname{pri} \mathrm{D}} \beta_{\mathrm{c} . \operatorname{pri} t}\right]
$$

Received: 29 January 2019 Accepted: 2 November 2019

Published online: 11 December 2019

\section{References}

Acemoglu D, Autor D (2011) Skills, tasks and technologies: implications for employment and earnings. Handb Labor Econ 4:1043-1171

Acosta P, Gasparini L (2007) Capital accumulation, trade liberalization, and rising wage inequality: The case of Argentina. Econ Dev Cult Change 55:793-812

Acosta P, Montes Rojas G (2008) trade reform and inequality: the case of Mexico and Argentina in the 1990s. World Econ 31:763-780

Alejo J, Bérgolo M, Carbajal F (2013) Las transferencias públicas y su impacto distributivo: la experiencia de los países del Cono Sur en la década de 2000 (No. 141). Documento de Trabajo

Alvaredo F, Gasparini L (2015) Recent trends in inequality and poverty in developing and emerging countries. In: Atkinson $A B$, Bourguignon $F$ (eds) Handbook of income distribution. Elsevier, Amsterdam, pp 697-805

Azevedo JP, Inchauste G, Sanfelice V (2012) Decomposing the recent inequality decline in Latin America. Mimeo, The World Bank, Washington, DC

Barro R, Lee J (2010) A New Data Set of Educational Attainment in the World, 1950-2010. NBER Working Paper 15902

Card D, Lemieux T (2001) Can falling supply explain the rising return to college for young men? Quart J Econ 116:705-746

Cord L, Barriga-Cabanillas O, Lucchetti L, Rodríguez-Castelán C, Sousa LD, Valderrama D (2017) Inequality stagnation in Latin America in the aftermath of the global financial crisis. Rev Dev Econ 21(1):157-181

Cruces G, García Domench C, Gasparini L (2014) Inequality in Education: Evidence for Latin America. In: En Cornea G (ed). Falling inequality in Latin America. Policy changes and lessons. Oxford University Press, Oxford, pp 318-339. (ISBN 978-0-19-870180-4)

Galiani S (2009) Salarios y Educación en el Mercado Laboral Panameño. Mimeo, New York City Gallego FA (2012) Skill premium in Chile: studying skill upgrading in the South. World Dev 40(3):594-609

García Swartz D, Gasparini L (2011) General-equilibrium perspectives on relative wage changes in a highly volatile macroeconomic environment: Argentina between 1974 and 1995. CEDLAS working paper

Gasparini L, Lustig N (2011) The rise and fall of income inequality in Latin America (No. 118). Documento de Trabajo Gasparini L, Cruces G, Tornarolli L (2011) Recent trends in income inequality in Latin America. Economia 10:147-201 Gasparini L, Cruces G, Tornarolli L (2016) Chronicle of a Deceleration Foretold: income Inequality in Latin America in the 2010s. Revista de Economía Mundial 43:25-46

Goldin CD, Katz LF (2009) The race between education and technology. Harvard University Press, Cambridge Katz L, Murphy K (1992) Changes in relative wages, 1963-1987: supply and demand factors. Quart J Econ 107:35-78 López-Calva L, Lustig N (2010) The new dynamics of income inequality in Latin America. Brookings Institution and UNDP, Washington DC

Manacorda M, Sánchez-Páramo C, Schady N (2010) Changes in returns to education in Latin America: the role of demand and supply of skills. Ind Labor Relat Rev 63:307-326

Montes Rojas G (2006) Skill premia in Mexico: demand and supply factors. Appl Econ Lett 13:917-924

Tinbergen J (1975) Income distribution: analysis and policies. University of Wisconsin Press, Madison

\section{Publisher's Note}

Springer Nature remains neutral with regard to jurisdictional claims in published maps and institutional affiliations. 